\title{
Snaring technique for explantation of transcatheter aortic valve bioprosthesis
}

\author{
Matthew Valdis ${ }^{1 \#}$, Fadi Hage ${ }^{1 \#}$, Pantelis Diamantouros ${ }^{2}$, Rodrigo Bagur ${ }^{2}$, Patrick Teefy ${ }^{2}$, Michael W. A. Chu ${ }^{1}$ \\ ${ }^{1}$ Division of Cardiac Surgery, Department of Surgery, ${ }^{2}$ Division of Cardiology, Department of Medicine, Western University, London Health \\ Sciences Center, London, Ontario, Canada \\ \#These authors contributed equally to this work. \\ Correspondence to: Michael W. A. Chu, MD, FRCSC. Professor of Surgery, Division of Cardiac Surgery, Department of Surgery, Western University, B6- \\ 106 University Hospital, London Health Sciences Center, 339 Windermere Rd., London, Ontario N6A 5A5, Canada. Email: Michael.Chu@lhsc.on.ca.
}

Submitted May 20, 2020. Accepted for publication Jun 02, 2020.

doi: $10.21037 /$ acs-2020-av-18

View this article at: http://dx.doi.org/10.21037/acs-2020-av-18

\section{Clinical vignette}

An 89-year-old male underwent transfemoral transcatheter aortic valve implantation (TAVI) with a $34 \mathrm{~mm}$ Medtronic Evolute $^{\mathrm{TM}} \mathrm{R}$ bioprothesis 12 months prior for symptomatic severe calcific aortic stenosis (NYHA class III). He presented to a peripheral hospital with a 6-week history of intermittent fever, malaise and acute debilitating back pain, leaving him hospitalized in a bedridden state. Investigations revealed a lumbar discitis, osteomyelitis and paravertebral/psoas abscess. Abscess drainage revealed coagulase negative Staphylococcus aureus and a course of vancomycin and rifampin were initiated, but the patient continued to experience recalcitrant fevers. His past medical history was significant for hypertension, hyperlipidemia, obstructive sleep apnea and previous prostate cancer. Transthoracic echocardiography demonstrated a stable mild paravalvular leak and an increase in transvalvular gradients (mean gradient $22 \mathrm{mmHg}$, peak gradient $44 \mathrm{mmHg}$ ). A transesophageal echocardiogram was eventually performed which revealed an $11 \times 12 \mathrm{~mm}$ mobile vegetation attached to the ventricular side of the transcatheter valve leaflet without evidence of aortic root abscess. The decision was made for an urgent TAVI valve explantation and surgical aortic valve replacement (AVR) for infectious source control.

\section{Surgical techniques}

\section{Preparation}

The operation was performed under general anesthesia in our hybrid operating room, although any operating theatre could suffice. Routine invasive monitoring and transesophageal echocardiography were employed and the patient prepared in a supine fashion.

\section{Exposition}

A midline or hemi-sternotomy was used to access the aortic root when appropriate and central cannulation employed. Mild hypothermia is preferred, antegrade cardioplegia is delivered via the aortic root or direct ostial cannulas and left ventricular venting is achieved via the right superior pulmonary vein.

\section{Operation}

A 'hockey-stick' shaped aortotomy is generally preferred, however often adjusted to navigate commonly present aortic calcification. The height of the aortotomy is tailored to the transcatheter prosthesis design and its protrusion into the ascending aorta. Generally, a low aortotomy (just above the sinotubular junction) works well for shorter balloon expandable prostheses; whereas, a higher aortotomy (3-4 $\mathrm{cm}$ above the right coronary artery) is more suitable for taller self-expanding prostheses. While it is tempting to make the aortotomy above the taller self-expanding prostheses, we believe an aortotomy placed $1 \mathrm{~cm}$ lower than the peak extent of tall transcatheter prostheses facilitates subsequent surgical valve replacement.

Following the aortotomy, great care is taken to 
circumferentially free the distal end of the CoreValve Evolut R stent frame from the ascending aortic wall, peeling the nitinol stent frame from the pannus formation and neointimalization. As seen in the video, the surgeon must carefully remove all of the pseudo-endothelial tissue to minimize risk of embolization and stroke without compromising integrity of the aortic wall. Despite most of these patients having calcified aortic roots with challenging anatomy, we still aim to perform an isolated AVR in most of these cases, reserving aortic root replacement only if necessary.

To facilitate explantation of the TAVI prosthesis, we weave a heavy silk suture through the most cranial cells of the TAVI prosthesis and snare down the prosthesis with a Rummel tourniquet to collapse the prosthesis and facilitate removal. If the prosthesis cannot be extracted with cranial force, then further collapse of the prosthesis is performed with a sponge stick and a rotational force to 'corkscrew' out the device. Once the TAVI prosthesis is removed, the native aortic valve leaflets are excised and annulus debrided, prior to implantation of a surgical bioprosthesis in the standard fashion.

\section{Completion}

After inspection of the implanted valve prosthesis and the aortic root intimal layer, any remaining pannus tissue is excised, followed by surgical excision of the native leaflets and debridement of the aortic annulus. The aortic valve is then sized, pledgeted aortic valve sutures are placed around the annulus and a surgical AVR is completed in the standard fashion. Following inspection of the implanted valve prosthesis and aortic root intimal layer, safe and hemostatic closure of the aortotomy is paramount, particularly with calcified aortas. The patient is weaned from cardiopulmonary bypass. Transesophageal echocardiography is routinely performed to assess valve function and ventricular function.

\section{Comments}

\section{Clinical results}

At our institution, we have explanted twelve transcatheter prostheses since 2009 using this technique and have not experienced any operative or 30-day mortality. We have been able to perform AVR alone in eleven patients, and only required aortic root replacement in one patient who had a porcelain aorta necessitating a complete replacement of the aortic root, ascending aorta and aortic arch.

\section{Advantages}

The snaring technique of the transcatheter prosthesis provides the surgeon with a reliable method to maneuver and distract the natural outward radial force of the self-expanding valve during careful dissection. This technique offers a more effective collapse in the prosthesis as compared to using ice-cold saline to allow the nitinol stent frame to collapse on its own, as has been described by others (1). Caution must be exercised to preserve the aortic root and ascending aortic walls to prevent injury, dissection or rupture. Other groups have described more aggressive techniques for TAVI explant with extensive aortic root endarterectomy and a large percentage of patients requiring total aortic root replacement afterwards (2). The technique described here allows for a less aggressive approach which is even more favourable in this elderly, frail and high-risk patient population.

\section{Caveats}

This technique is most useful for self-expanding transcatheter prostheses which often extend well up into the ascending aorta. However, it may be less advantageous for lower profile balloon expandable valves that can be mechanically crushed or folded using surgical clamps, with less concern about causing unwanted damage to the ascending aorta or aortic root when removing the transcatheter aortic prosthesis.

\section{Acknowledgments}

Funding: None.

\section{Footnote}

Conflicts of Interest: MWAC has received Speakers' honoraria from Medtronic, Edwards Lifesciences, Boston Scientific, Terumo Aortic and Abbott Vascular. PD has received Proctorship fees from Boston Scientific. The other authors have no conflicts of interest to declare.

Open Access Statement: This is an Open Access article distributed in accordance with the Creative Commons Attribution-NonCommercial-NoDerivs 4.0 International License (CC BY-NC-ND 4.0), which permits the noncommercial replication and distribution of the article with 
the strict proviso that no changes or edits are made and the original work is properly cited (including links to both the formal publication through the relevant DOI and the license). See: https://creativecommons.org/licenses/by-nc-nd/4.0/.

\section{References}

1. Mangi AA, Ramchandani M, Reardon M. Surgical removal

Cite this article as: Valdis M, Hage F, Diamantouros P, Bagur R, Teefy P, Chu MWA. Snaring technique for explantation of transcatheter aortic valve bioprosthesis. Ann Cardiothorac Surg 2020;9(6):534-536. doi: 10.21037/acs-2020-av-18 and replacement of chronically implanted transcatheter aortic prostheses: how I teach it. Ann Thorac Surg 2018;105:12-4.

2. Fukuhara S, Brescia AA, Shiomi S, et al. Surgical explantation of transcatheter aortic bioprostheses: results and clinical implications. J Thorac Cardiovasc Surg 2020. [Epub ahead of print]. 